
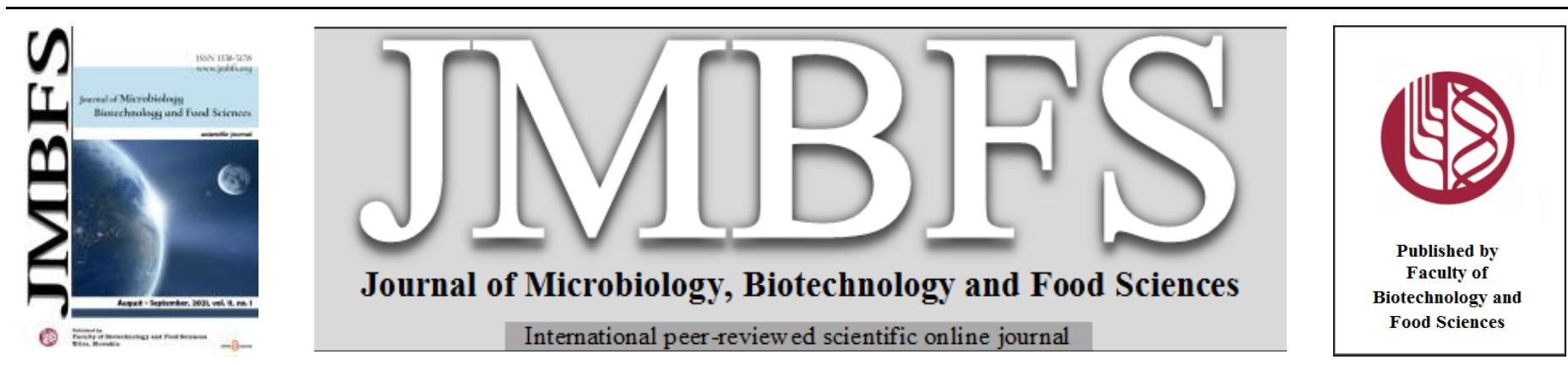

\title{
NOVEL ASSESSMENT OF SYNERGISTIC STIMULATORY EFFECT OF PREBIOTIC CHITOOLIGOSACCHARIDE AND SOME COMMERCIAL PREBIOTICS ON THE PROBIOTIC GROWTH: A PRELIMINARY STUDY
}

\author{
Hoda S. El-Sayed ${ }^{1}$, Shaymaa Ismail ${ }^{2}$, Bahgat Fayed $^{2,3 *}$ \\ Address(es): Bahgat Fayed, \\ ${ }^{1}$ Dairy Science Department, National Research Centre, Dokki, Cairo, 12622, Egypt. \\ ${ }^{2}$ Chemistry of Natural and Microbial Product, National Research Centre, Dokki, Cairo, 12622, Egypt. \\ ${ }^{3}$ Sharjah Institute for Medical Research, University of Sharjah, P.O. Box 27272, Sharjah, United Arab Emirates.
}

*Corresponding author: bfayed@ sharjah.ac.ae

https://doi.org/10.15414/jmbfs.3341

ARTICLE INFO

Received 26. 6. 2020

Revised 28. 1. 2021

Accepted 2. 2. 2021

Published 1. 8. 2021

Regular article

open $\partial_{\text {ACCESS }}$

\section{ABSTRACT}

This study investigates the possible synergistic stimulatory effects of prebiotic chitooligosaccharide and some commercial prebiotics on probiotic growth. Different combination of chitooligosaccharide with inulin, fructooligosaccharide, and lactulose were prepared and their ability to stimulate the growth of probiotic strains was evaluated. Following Chou-Talalay method, the combination index was calculated and used for synergistic assessment. The data showed that most of the prebiotics combinations showed synergism with different magnitudes depending on the prebiotic type, concentration and the probiotic strain employed in the study. It was indicated from the combination index that the combination between chitooligosaccharide and fructooligosaccharide has higher synergism compared to the combination of chitooligosaccharide with lactulose or inulin. Additionally, as the concentration of prebiotics increased, the synergistic effect increased. Synergism was also affected by the probiotic strain employed, since a higher synergism was shown with Bifidobacterium lactis when compared to Lactobacillus helveticus. It was concluded that combining chitooligosaccharide with commercial prebiotics produced synergistic effect on the probiotic proliferation. The synergism was further dependent on the type and concentration of the combined prebiotic and on the probiotic strain used in the study.

Keywords: Chitooligosaccharide, Bifidobacterium lactis, Combination index, Inulin, Synergism

\section{INTRODUCTION}

The human digestive system is colonized by a complex ecosystem of 100 trillion microorganisms that are essential for gastrointestinal homeostasis (Ouwehand and Vaughan, 2006). Several environmental factors including smoking (Biedermann et al., 2013), unbalanced diet (Scott et al., 2013), and lack of physical activity (Clarke $\boldsymbol{e t}$ al., 2014) have been evaluated for the qualitative and quantitative composition of that ecosystem. The disturbance in the composition of these microorganisms has been correlated to some gastrointestinal diseases in addition to cardiovascular and emotional disorders. Moreover, restoring the balance of intestinal microbiota has been indicated to improve the health of those patients and prevent complications (Bailey and Cryan, 2017; Feng et al., 2018). Hence, it is always desirable to maintain and restore the balance of intestinal microbiota to maintain beneficial health effects.

Probiotic administration has been known for long time to be the main agents influencing the composition of intestinal microbiota. They are defined according to the Food and Agriculture Organization of the United Nations and World Health Organization (Report FAO/WHO, 2001) as "live microorganisms which when administered in adequate amounts confer a health benefit on the host". Czinn and Blanchard, 2009 reported that the minimum daily intake of probiotics to show its health benefits was $10^{8}-10^{10}$ cfu (cells-colony forming unit). In the last decade, a large number of food products and beverages enriched by probiotics (such as Lactobacilli and Bifidobacteria) are commercially produced (Sanders et al., 2019).

On the other hand, prebiotics are food components that selectively boost the microbiota proliferation in the intestinal tract. The International Scientific Association for Probiotics and Prebiotics (ISAPP) in 2016 revised the prebiotic definition to 'a substrate that is selectively utilized by host microorganisms conferring a health benefit' (Gibson et al., 2017). Although this definition expanded the utilization of different substrates including inorganic and organic substances as prebiotics, non-digestible carbohydrates including galactans and fructans are known as the most widely applied substrates. Several clinical studies demonstrated the positive modulation of the intestinal microbiota by prebiotic consumption. Drakoularakou et al., 2010 and Hasle et al., 2017 reported a significant reduction in the incidence of travelers' diarrhea by the consumption of $\beta$-galacto-oligosaccharides. In addition, inulin has been found to be efficient in the reduction of adults and children constipation (Yurrita et al., 2014; ClosaMonasterolo et al., 2017). Another study by Staudacher \& Whelan., 2016 and Vulevic et al., 2018 reported a significant improvement in some gastrointestinal symptoms of irritable bowel syndrome by the consumption of $\beta$-galactooligosaccharides.

The synergistic benefits of combining the prebiotics with the probiotic bacteria (synbiotics) in food supplement to boost the intestinal microbiota has been explored by various scientific literatures (Femia et al., 2002; Crittenden et al., 2003; Bartosch et al., 2005; Cook et al., 2014; Westfall et al., 2018; Fayed et al., 2018; Maftei., 2019). The consumption of Bifidobacterium animalis subsp. Lactis 420 in combination with Litesse Ultra ${ }^{\mathrm{TM}}$ polydextrose led to modulation of the gut microbiota that may support the improvement in the function of the gut barrier and the obesity-related markers (Hibberd et al., 2019). Shimizu et al., 2018, also indicated the modulation of the gut microbiota after the consumption of Bifidobacterium breve strain Yakult, Lactobacillus casei with galactooligosaccharides suggesting its preventive effect on the incidence of enteritis and ventilator-associated pneumonia in patients with sepsis.

As the consumed probiotic strain must compete with an already established microbiota, it was found that the synergistic effect of combining probiotic bacteria and prebiotics can be related to the ability of the probiotic bacteria to adapt to the prebiotic substrate prior to consumption which provides an advantage for synbiotic consumption over the consumption of probiotics alone (Bandyopadhyay and Mandal, 2014).

Although, the market contains prebiotic supplements that claim the preference of administrating prebiotics combination over administrating one type only and few studies showed that the health benefits were boosted when prebiotics were used in combination (Lecerf $\boldsymbol{e t} \boldsymbol{a l}$., 2012), no scientific literature has studied the benefit of combining the prebiotics together on the microbiota proliferation and the potential synergism that could developed by such combination.

Formerly, we have produced chitooligosacchride (COS) from the enzymatic hydrolysis of chitosan and its prebiotic stimulatory activity was confirmed (Ismail et al., 2020). Generally, COS are either homo or hetero linear oligomers 
of glucosamine and/or N-acetyl-D-glucosamine linked by $\beta$-1,4-glycosidic linkages with a degree of polymerization ranged from 2 to 20 units and with an average molecular weight less than 3.9KDa (Muzzarelli., 1993).

In the present study, we have evaluated for the first time to our knowledge the possible synergistic effect of combining COS with fructooligosaccharide (FOS), lactulose, and inulin on the growth of probiotics by calculating the combination index of each mixture under the study.

\section{MATERIAL AND METHODS}

\section{Bacterial strains}

Bifidobacterium lactis BB12 was obtained from Northern Regional Research Laboratory (NRRL), Agriculture Research Service, National Center for Agriculture, Peoria, Illinois, USA. Lactobacillus helveticus CNRZ 32 was supplemented from Centre National de RechercheZoo technique, Jouy-en-Josas, France.

\section{Production of chitooligosaccharide}

Chitooligosaccharide was produced by the hydrolysis of chitosan employing chitosanase enzyme produced from fermentation of shrimp byproducts using Bacillus cereus strain SSW1 as previously described by Ismail., 2019.

Assessment of possible synergism between chitooligosaccharide and commercial prebiotics

Two probiotic strains, Bifidobacterium lactis BB12 and Lactobacillus helveticus were grew on De Man, Rogosa and Sharpe broth (MRS) for $48 \mathrm{~h}$ at $37^{\circ} \mathrm{C}$ Samples were taken and cell counts were determined by the pour plate method using MRS agar according to Azmi et al., 2012.

Table 1 Prebiotic mixtures formulated along the study.

\begin{tabular}{|c|c|c|c|c|}
\hline \multirow[b]{2}{*}{$\begin{array}{l}\text { Combination } \\
\text { number }\end{array}$} & \multicolumn{2}{|c|}{ Prebiotic 1} & \multicolumn{2}{|c|}{ Prebiotic 2} \\
\hline & Type & $\begin{array}{c}\text { Concentration } \\
(w / v \%)\end{array}$ & Type & $\begin{array}{c}\text { Concentration } \\
(\mathbf{w} / \mathbf{v} \%)\end{array}$ \\
\hline $\mathrm{C} 1$ & - & - & FOS & 0.25 \\
\hline $\mathrm{C} 2$ & - & - & FOS & 0.5 \\
\hline $\mathrm{C} 3$ & - & - & FOS & 1 \\
\hline $\mathrm{C} 4$ & $\mathrm{COS}$ & 0.25 & - & - \\
\hline C5 & $\mathrm{COS}$ & 0.25 & FOS & 0.25 \\
\hline C6 & $\operatorname{COS}$ & 0.25 & FOS & 0.5 \\
\hline $\mathrm{C} 7$ & $\mathrm{COS}$ & 0.25 & FOS & 1 \\
\hline $\mathrm{C} 8$ & $\mathrm{COS}$ & 0.5 & - & - \\
\hline $\mathrm{C} 9$ & COS & 0.5 & FOS & 0.25 \\
\hline $\mathrm{C} 10$ & $\operatorname{COS}$ & 0.5 & FOS & 0.5 \\
\hline $\mathrm{C} 11$ & $\mathrm{COS}$ & 0.5 & FOS & 1 \\
\hline $\mathrm{C} 12$ & $\mathrm{COS}$ & 1 & - & - \\
\hline $\mathrm{C} 13$ & $\operatorname{COS}$ & 1 & FOS & 0.25 \\
\hline $\mathrm{C} 14$ & $\mathrm{COS}$ & 1 & FOS & 0.5 \\
\hline $\mathrm{C} 15$ & $\mathrm{COS}$ & 1 & FOS & 1 \\
\hline $\mathrm{C} 17$ & - & - & Lactulose & 0.25 \\
\hline $\mathrm{C} 18$ & - & - & Lactulose & 0.5 \\
\hline C19 & - & - & Lactulose & 1 \\
\hline $\mathrm{C} 20$ & $\mathrm{COS}$ & 0.25 & Lactulose & 0.25 \\
\hline $\mathrm{C} 21$ & COS & 0.25 & Lactulose & 0.5 \\
\hline $\mathrm{C} 22$ & $\mathrm{COS}$ & 0.25 & Lactulose & 1 \\
\hline $\mathrm{C} 23$ & $\mathrm{COS}$ & 0.5 & Lactulose & 0.25 \\
\hline $\mathrm{C} 24$ & COS & 0.5 & Lactulose & 0.5 \\
\hline $\mathrm{C} 25$ & COS & 0.5 & Lactulose & 1 \\
\hline $\mathrm{C} 26$ & $\mathrm{COS}$ & 1 & Lactulose & 0.25 \\
\hline $\mathrm{C} 27$ & COS & 1 & Lactulose & 0.5 \\
\hline $\mathrm{C} 28$ & COS & 1 & Lactulose & 1 \\
\hline $\mathrm{C} 29$ & - & - & Inulin & 0.25 \\
\hline $\mathrm{C} 30$ & - & - & Inulin & 0.5 \\
\hline C31 & - & - & Inulin & 1 \\
\hline $\mathrm{C} 32$ & COS & 0.25 & Inulin & 0.25 \\
\hline $\mathrm{C} 33$ & $\mathrm{COS}$ & 0.25 & Inulin & 0.5 \\
\hline C34 & COS & 0.25 & Inulin & 1 \\
\hline $\mathrm{C} 35$ & $\mathrm{COS}$ & 0.5 & Inulin & 0.25 \\
\hline C36 & $\mathrm{COS}$ & 0.5 & Inulin & 0.5 \\
\hline C37 & $\mathrm{COS}$ & 0.5 & Inulin & 1 \\
\hline C 38 & COS & 1 & Inulin & 0.25 \\
\hline C39 & COS & 1 & Inulin & 0.5 \\
\hline $\mathrm{C} 40$ & $\mathrm{COS}$ & 1 & Inulin & 1 \\
\hline
\end{tabular}


depending on the COS and FOS concentration. The maximum viable count was $1.06 \times 10^{10} \pm 2.8 \times 10^{8} \mathrm{CFU} / \mathrm{mL}$ at $1 \%$ concentration for both COS and FOS.

A

- $0 \%$ FOS $\quad \mathbf{v} 0.25 \%$ FOS $\quad$ I $0.5 \%$ FOS $\quad$ L $1 \%$ FOS

है

$1,40 \mathrm{E}+09$
$1,20 \mathrm{E}+09$
$1,00 \mathrm{E}+09$
$8,00 \mathrm{E}+08$
$6,00 \mathrm{E}+08$
$4,00 \mathrm{E}+08$
$2,00 \mathrm{E}+08$
$0,00 \mathrm{E}+00$

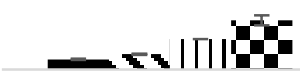

$0 \% \cos$

B
- $0.25 \%$ Lactulose

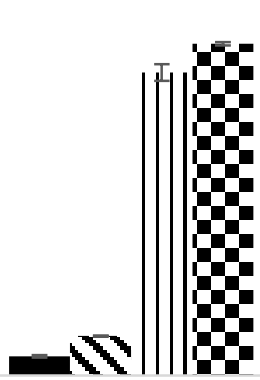

$0.5 \% \cos$

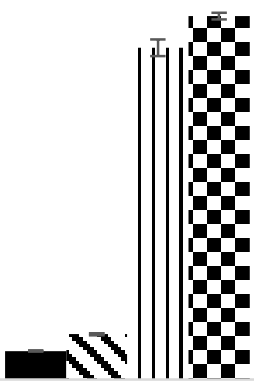

$1 \% \mathrm{COS}$

$$
\text { ธ } 0 \% \text { Lactulose }
$$

、 $0.5 \%$ Lactulose

I $1 \%$ Lactulose

音

$3,00 \mathrm{E}+08$

$2,50 \mathrm{E}+08$

$2,00 \mathrm{E}+08$

$1,50 \mathrm{E}+08$

$1,00 \mathrm{E}+08$

$5,00 \mathrm{E}+07$

$0,00 \mathrm{E}+00$

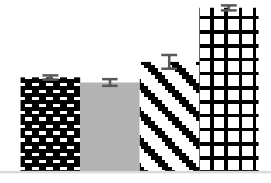

$0 \% \cos$

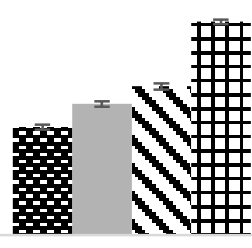

$0.25 \% \operatorname{COS}$

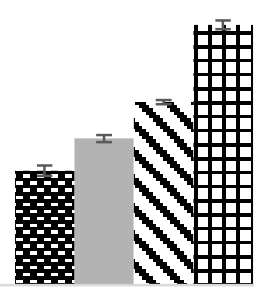

$0.5 \% \operatorname{COS}$

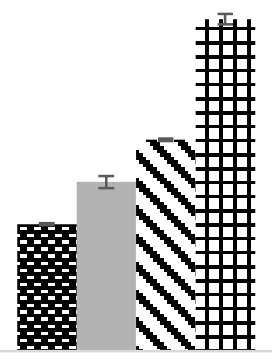

$1 \% \operatorname{COS}$

C

$-0 \%$ inulin

$.0 .25 \%$ Inulin

$0.5 \%$ Inulin

$\therefore 1 \%$ Inulin

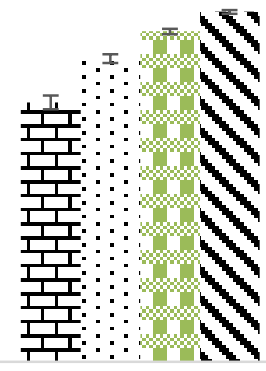

$0 \% \cos$

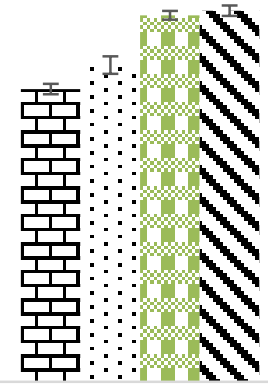

$0.25 \% \cos$

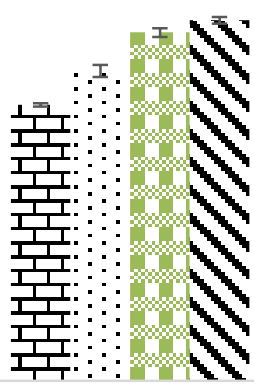

$0.5 \% \cos$

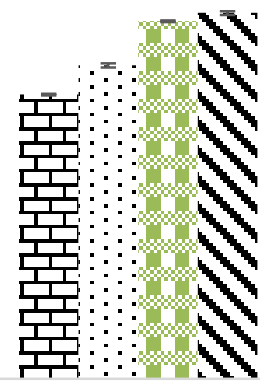

$1 \% \operatorname{COS}$

Figure 1 Lactobacillus helveticus viable count in the presence of (A) COS and/or FOS at different concentration $(0.25 \%, 0.5 \%, 1 \%)$ (B) COS and/or lactulose at different concentration $(0.25 \%, 0.5 \%, 1 \%)(\mathrm{C}) \mathrm{COS}$ and/or inulin at different concentration $(0.25 \%, 0.5 \%, 1 \%)$. The effects of prebiotics were tested compared to prebiotic free media as negative control. The data display the mean \pm standard error (SEM) of three replicas 
A

$1,00 \mathrm{E}+10$

$8,00 \mathrm{E}+09$

$6,00 \mathrm{E}+09$

$4,00 \mathrm{E}+09$

$2,00 \mathrm{E}+09$

$0,00 \mathrm{E}+00$

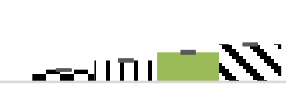
$0 \% \cos$

x $0 \%$ Lactulose

$0.25 \%$ Lactulose

$0.5 \%$ Lactulose

- $1 \%$ Lactulose

$1,00 \mathrm{E}+09$

$0,00 \mathrm{E}+00$

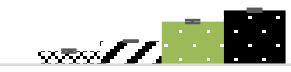

$0 \% \operatorname{COS}$

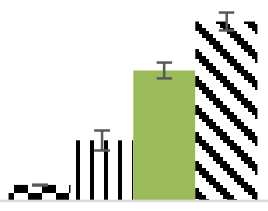

$0.25 \% \cos$

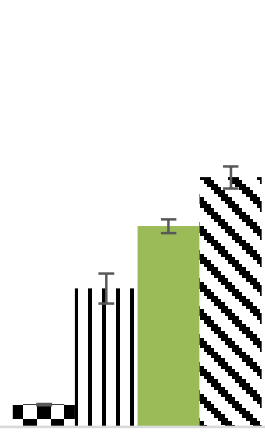

$0.5 \% \cos$

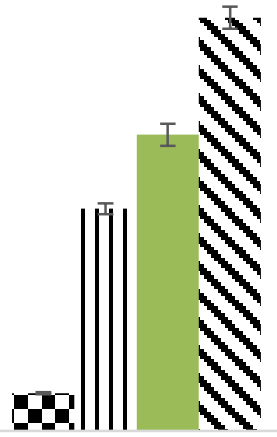

$1 \% \cos$

C

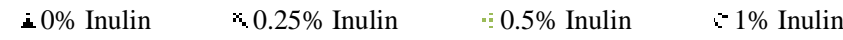

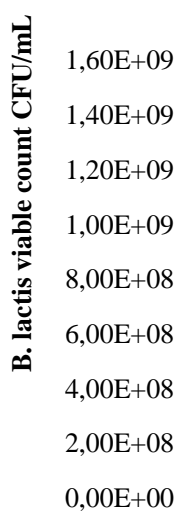

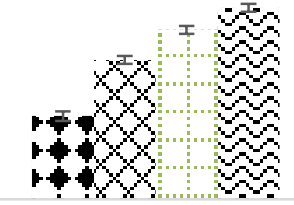

$0 \% \cos$

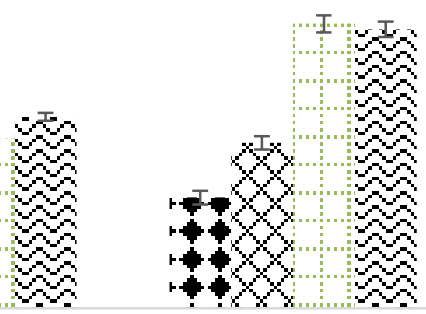

$0.25 \% \cos$

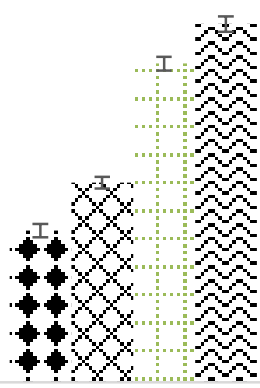

$0.5 \% \operatorname{COS}$

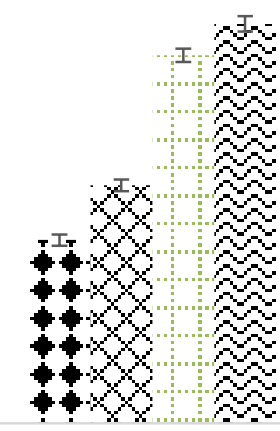

$1 \% \operatorname{COS}$

Figure 2 Bifidobacterium lactis viable count in the presence of (A) COS and/or FOS at different concentration $(0.25 \%, 0.5 \%, 1 \%)$ (B) COS and/or lactulose at different concentration $(0.25 \%, 0.5 \%, 1 \%)(\mathrm{C}) \mathrm{COS}$ and/or inulin at different concentration $(0.25 \%, 0.5 \%, 1 \%)$. The effects of prebiotics were tested compared to prebiotic free media as negative control. The data display the mean \pm standard error (SEM) of three replicas.

Effect of combining chitooligosaccharide and lactulose on the viability of Bifidobacterium lactis

It was observed according to Figure $2 \mathrm{~B}$, that the viable count of Bifidobacterium lactis in the absence of COS and lactulose was $2.3 \times 10^{8} \pm 2.12 \times 10^{7} \mathrm{CFU} / \mathrm{mL}$ after incubation for $48 \mathrm{~h}$ at $37^{\circ} \mathrm{C}$. The viable count was slightly enhanced to $9.15 \times 10^{8} \pm$ $2.47 \times 10^{7} \mathrm{CFU} / \mathrm{mL}$ and $4.3 \times 10^{8} \pm 4.6 \times 10^{7} \mathrm{CFU} / \mathrm{mL}$ by adding either lactulose or $\mathrm{COS}$, respectively at $1 \%$ concentration. By mixing both prebiotics together the viable count significantly increased to reach $4.93 \times 10^{9} \pm 2.12 \times 10^{8} \mathrm{CFU} / \mathrm{mL}$ at a concentration of $1 \%$ for both COS and lactulose.
Effect of combining chitooligosaccharide and inulin on the viability of Bifidobacterium lactis

Chitooligosaccharide and inulin were combined at different concentrations ranging from $0.25 \%$ to $1 \%$ to study the potential effect on the viability of Bifidobacterium lactis. The data showed that the viable count was $3.05 \times 10^{8} \pm$ $1.77 \times 10^{7} \mathrm{CFU} / \mathrm{mL}$ when the $\mathrm{COS}$ and inulin were not added to the culture media after $48 \mathrm{~h}$ incubation period. The viable count was enhancement to $6.7 \times 10^{8} \pm$ $2.12 \times 10^{7} \mathrm{CFU} / \mathrm{mL}$ and $7 \times 10^{8} \pm 1.41 \times 10^{7} \mathrm{CFU} / \mathrm{mL}$ when the $\mathrm{COS}$ and inulin were added separately at $1 \%$ concentration for each. However, significant improvement in Bifidobacterium lactis viability was observed when the two 
prebiotics were combined together at concentration $1 \%$ for each of them to reach $1.46 \times 10^{9} \pm 2.83 \times 10^{7} \mathrm{CFU} / \mathrm{mL}$ (Figure 2C).

\section{Synergistic stimulatory effect of combining COS with other prebiotics on the} viability of Lactobacillus helveticus

The synergistic effect of combining COS with any of FOS, lactulose, and inulin was evaluated by calculating the $\mathrm{CI}$ index of each combination at different concentrations of each prebiotic. Table 2, showed the CI index of all prebiotic combinations that were employed using Lactobacillus helveticus. Some combinations (C5, C6, C7, C10, C11, C13, C15, C24, C25, C27, C28, C37, C39 and C40) showed significant synergism, since the CI index was less than 0.5 , while the rest showed moderate synergism with $\mathrm{CI}$ value between 0.5 and 0.9 except C35 which showed weak synergism, while C32 and C34 displayed weak antagonist effect.
Synergistic stimulatory effect of combining COS with other prebiotics on the viability of Bifidobacterium lactis

The synergism between COS and FOS, lactulose, and inulin on stimulating the viability of Bifidobacterium lactis was indicated in Table 3. The data reveled that most of the prebiotic combinations under study showed higher synergistic effect with CI value less than 0.5 except 5 combinations including C20, C23, C32, C35, and $\mathrm{C} 38$, which showed moderate synergistic effects, since their $\mathrm{CI}$ values were in the range of 0.5 to 0.9 . The observed data indicated that no prebiotic combination under study showed weak synergistic effect, additive effect or antagonist effect.

Table 2 Combination index of COS combined with other prebiotics to stimulate Lactobacillus helveticus viability

\begin{tabular}{|c|c|c|c|c|c|}
\hline $\begin{array}{l}\text { Combination } \\
\text { number }\end{array}$ & Combination index & $\begin{array}{c}\text { Combination } \\
\text { number }\end{array}$ & Combination index & $\begin{array}{c}\text { Combination } \\
\text { number }\end{array}$ & Combination index \\
\hline C5 & 0.47117 & $\mathrm{C} 21$ & 0.70047 & C34 & 1.35724 \\
\hline C6 & 0.07636 & $\mathrm{C} 22$ & 0.57795 & $\mathrm{C} 35$ & 0.89053 \\
\hline $\mathrm{C} 7$ & 0.12863 & $\mathrm{C} 23$ & 0.51641 & $\mathrm{C} 36$ & 0.54018 \\
\hline $\mathrm{C} 9$ & 0.52143 & $\mathrm{C} 24$ & 0.46669 & C37 & 0.19331 \\
\hline $\mathrm{C} 10$ & 0.06314 & $\mathrm{C} 25$ & 0.37991 & C38 & 0.75520 \\
\hline $\mathrm{C} 11$ & 0.11431 & $\mathrm{C} 26$ & 0.48507 & C39 & 0.44894 \\
\hline C13 & 0.63763 & $\mathrm{C} 27$ & 0.33880 & $\mathrm{C} 40$ & 0.29365 \\
\hline C14 & 0.06091 & $\mathrm{C} 28$ & 0.21790 & & \\
\hline $\mathrm{C} 15$ & 0.10352 & C32 & 1.34417 & & \\
\hline $\mathrm{C} 20$ & 0.58669 & C33 & 0.83611 & & \\
\hline
\end{tabular}

Table 3 Combination index of COS combined with other prebiotics to stimulate Bifidobacterium lactis viability

\begin{tabular}{|c|c|c|c|c|c|}
\hline $\begin{array}{l}\text { Combination } \\
\text { number }\end{array}$ & Combination index & $\begin{array}{c}\text { Combination } \\
\text { number }\end{array}$ & Combination index & $\begin{array}{c}\text { Combination } \\
\text { number }\end{array}$ & Combination index \\
\hline $\mathrm{C} 5$ & 0.20512 & $\mathrm{C} 21$ & 0.04753 & C34 & 0.29766 \\
\hline C6 & 0.04412 & $\mathrm{C} 22$ & 0.07239 & $\mathrm{C} 35$ & 0.62740 \\
\hline $\mathrm{C} 7$ & 0.02454 & $\mathrm{C} 23$ & 0.64964 & $\mathrm{C} 36$ & 0.17530 \\
\hline C9 & 0.05490 & $\mathrm{C} 24$ & 0.04681 & $\mathrm{C} 37$ & 0.18800 \\
\hline $\mathrm{C} 10$ & 0.02460 & $\mathrm{C} 25$ & 0.04092 & C38 & 0.62865 \\
\hline C11 & 0.01316 & $\mathrm{C} 26$ & 0.06823 & C39 & 0.18096 \\
\hline C13 & 0.03165 & $\mathrm{C} 27$ & 0.02231 & $\mathrm{C} 40$ & 0.16421 \\
\hline $\mathrm{C} 14$ & 0.01139 & $\mathrm{C} 28$ & 0.00721 & & \\
\hline $\mathrm{C} 15$ & 0.00039 & $\mathrm{C} 32$ & 0.84925 & & \\
\hline $\mathrm{C} 20$ & 0.62561 & $\mathrm{C} 33$ & 0.17592 & & \\
\hline
\end{tabular}

\section{DISCUSSION}

The application of prebiotics as a nutrient supplement has been expanded over the last decade. Recent records provided by Global Prebiotic Association showed that the global sales of prebiotics supplements reached USD 5.5 billion in 2019 and is expected to reach USD 8.34 billion by 2026 (Report and data., 2019) Most of the prebiotic supplements in the market are in the form of prebiotic mixture that can selectively stimulate the gut microbiota. Despite the global market gross of prebiotics and the preference of most producers to fabricate the prebiotic supplements in mixture form, no data is available regarding the potential synergism that could be demonstrated by administrating more than one prebiotic. In our former work, we have produced COS that showed poten prebiotic activity compared to other commercial prebiotics such as inulin and FOS (Ismail et al., 2020). In order to further enhance the prebiotic activity of COS, in addition to expand its market value, we have mixed COS with differen concentrations of commercial prebiotics followed by analyzing the synergism between the tested mixtures. The Chou-Talalay method is based on the medianeffect equation derived from the mass action law theory. Since the median is a common link and universal reference point in biological systems, the ChouTalalay method has considered the mechanism independent, drug unit independent and dynamic order independent (Chou., 2010). Consequently, the method is recommended to measure the synergism in any biological system as long as the biological effect and the bioactive compound concentration that can be measured numerically. To apply this method here, we have considered the viable count of the probiotic bacteria as the biological effect produced by the prebiotic concentrations under study. Besides using more than one type of prebiotic in the current research in different concentrations, we have also employed two different probiotic bacteria. Our objective was initially to examine whether the synergism between prebiotics is really existing and further to clarify if the synergism is related to the prebiotic type or is related to the probiotic strain. It was clear demonstrated that synergism is definitely exists between prebiotics as most of the combination under study showed CI below 1 with some combinations even reached $\mathrm{CI}$ closer to 0.1 that indicates extreme synergism. Comparing the $\mathrm{CI}$ of prebiotic combination within the same strain, the results obviously showed that prebiotic type is one of the factors responsible for the synergism between prebiotics. By exploring CI data on Lactobacillus helveticus, it was clear indicated that the combination of COS with FOS showed significantly lower CI (more synergism) than the combination between COS and lactulose at the same concentration level which in turn showed lower CI (more synergism) than the combination between COS and inulin. The same pattern was also observed with Bifidobacterium lactis. The identical pattern in the two strains indicated the significance of careful selection of prebiotic type when designing a prebiotic mixture for the market use. Another indication can be extracted from the data regarding the prebiotic concentrations, it was clear observed that most of the combinations that include $0.25 \%$ concentration from any prebiotic have shown lower synergism compared to the other concentrations $(0.5 \%$ and $1 \%)$ suggesting that prebiotic concentration has an impact on the synergism between prebiotics. Finally, comparing the CI data between the two strains under study at the same prebiotic type and concentration level has definitely confirmed that the probiotic strain is another factor that determines the value of synergism between prebiotics. All the prebiotic combinations showed CI values on Lactobacillus helveticus higher than CI values on Bifidobacterium lactis except two combinations including $\mathrm{C} 20$, and $\mathrm{C} 23$. In our future work, we are planning to assess other types of prebiotics and evaluate a wide range of prebiotic concentrations to widen the knowledge regarding the synergism between prebiotics.

Acknowledgement: This research did not receive any specific grant from funding agencies in the public, commercial, or not for profit sectors.

Declaration of interest statement: The author reports no conflict of interest.

\section{REFERENCES}

Azmi, A. F., Mustafa, S., Hashim, D. M., \& Manap, Y. A. (2012). Prebiotic activity of polysaccharides extracted from Gigantochloa levis (Buluh beting) shoots. Molecules. 17, 1635-51. https://doi:10.3390/molecules 17021635.

Bailey, M. T., \& Cryan, J. F. (2017). The microbiome as a key regulator of brain, behavior and immunity: commentary on the 2017 named series. Brain Behav Immun. 66, 18-22. https://doi:10.1016/j.bbi.2017.08.017.

Bandyopadhyay, B., Mandal, N. C. (2014). Probiotics, prebiotics and synbioticsin health improvement by modulating gut microbiota: The concept revisited. Int 
J. Curr Microbiol App Sci. 3, 410-20. https://www.ijcmas.com/vol-33/Biplab\%20Bandyopadhyay\%20and\%20Narayan\%20C.\%20Mandal.pdf.

Bartosch, S., Woodmansey, E. J., Paterson, J. C., McMurdo, M. E., \& Macfarlane, G. T. (2005). Microbiological effects of consuming a synbiotic containing Bifidobacterium bifidum, Bifidobacterium lactis, and oligofructose in elderly persons, determined by real-time polymerase chain reaction and counting of viable bacteria. Clin. Infect. Dis. 40, 28-37. https://doi.org/10.1086/426027.

Biedermann, L., Zeitz, J., Mwinyi, J., Sutter-Minder, E., Rehman, A., Ott, S. J., \& et al. (2013). Smoking cessation induces profound changes in the composition of the intestinal microbiota in humans. PLoS One. 8, e59260. https://doi:10.1371/journal.pone.0059260.Epub2013.

Chou, T. C. (2010). Drug combination studies and their synergy quantification using the Chou-Talalay method. Cancer res. 70, 440-46. http://doi:10.1158/0008-5472.CAN-09-1947.

Clarke, S. F., Murphy, E. F., O'Sullivan, O., Lucey, A. J., Humphreys, M. Hogan, A.,\& et al. (2014). Exercise and associated dietary extremes impact on gut microbial diversity. Gut. 63, 1910-20. https://doi:10.1136/gutjnl-2013$\underline{306541}$.

Closa-Monasterolo, R. Gispert-Llaurado, M., Canals, J., Luque, V., ZaragozaJordana, M., Koletzko, B., \& et al. (2017). The effect of postpartum depression and current mental health problems of the mother on child behaviour at eight years. Matern. Child Health j. 21, 1563-72. https://doi.org/10.1007/s10995-0172288-x.

Cook,M. T., Tzortzis, G., Charalampopoulos, D., \& Khutoryanskiy, V. V. (2014). Microencapsulation of a synbiotic into PLGA/ multiparticulate gels. Int J. Pharm. 466, 400-408. https://doi.org/10.1016/j.ijpharm.2014.03.034.

Crittenden, R. G., Martinez, N. R., \& Playne, M. J. (2003). Synthesis and utilisation of folate by yoghurt starter cultures and probiotic bacteria. Int $\mathrm{J}$ food microbiol. 80, 217-22. https://doi.org/10.1016/S0168-1605(02)00170-8.

Czinn, S. J., \& Blanchard, S. S. (2009). Probiotics in foods and supplements, in: Probiotics in pediatric medicine. Humana Press. pp. 299. 306.https://www.researchgate.net/profile/George Fuchs/publication/22718834.

Drakoularakou, A., Tzortzis, G., Rastall, R. A., \& Gibson, G. R. (2010). A double-blind, placebo-controlled, randomized human study assessing the capacity of a novel galacto-oligosaccharide mixture in reducing travellers' diarrhoea. Eur. J. Clin. Nutr. 64, 146-52. https://doi.org/10.1038/ejcn.2009.120.

Fayed, B., Abood, A., El-Smn ayed, H. S., Hashem, A. M., \& Mehanna, N. S. (2018). A synbiotic multiparticulate microcapsule for enhancing inulin intestinal release and Bifidobacterium gastro-intestinal survivability. Carbohydr. polym. 193, 137-43. https://doi.org/10.1016/j.carbpol.2018.03.068.

Femia, A. P., Luceri, C., Dolara, P., Giannini, A., Biggeri, A., \& Salvadori, M., et al. (2002). Antitumorigenic activity of the prebiotic inulin enriched with oligofructose in combination with the probiotics Lactobacillus rhamnosus and Bifidobacterium lactis on azoxymethane-induced colon carcinogenesis in rats. Carcinogenesis. 23, 1953-60. https://doi.org/10.1093/carcin/23.11.1953.

Feng, Q., Chen, W. D., \& Wang, Y. D. (2018). Gut microbiota: an integral moderator in health and disease. Front. Microbiol. 9, 151 https://doi:10.3389/fmicb.2018.00151.

Gibson, G. R., Hutkins, R., Sanders, M. E., Prescott, S. L., Reimer, R. A., \& Salminen, S. J., et al. (2017). Expert consensus document: the International Scientific Association for Probiotics and Prebiotics (ISAPP) consensus statement on the definition and scope of prebiotics. Nat. Rev. Gastroenterol. Hepatol. 8, 491-502. https://doi.10.1038/nrgastro.2014.66.

Hasle, G., Raastad, R., Bjune, G., Jenum, P. A., \& Heier, L. (2017). Can a galacto-oligosaccharide reduce the risk of traveller's diarrhoea? A placebocontrolled, randomized, double-blind study. J. Travel Med. 24, tax057. https://doi.org/10.1093/jtm/tax057.

Hibberd, A. A., Yde, C. C., Ziegler, M. L., Honoré, A. H., Saarinen, M. T., \& Lahtinen, S., et al. (2019). Probiotic or synbiotic alters the gut microbiota and metabolism in a randomised controlled trial of weight management in overweight adults. Benef. microbes. 10, 121-35. https://doi.org/10.3920/BM2018.0028.

Ismail, S. A., (2019). Microbial valorization of shrimp byproducts via the production of thermostable chitosanase and antioxidant $\begin{array}{llll}\text { chitooligosaccharides. Biocat Agri Biotechnol. 20, } 101269 & \end{array}$ https://doi.org/10.1016/j.bcab.2019.101269.

Ismail, S. A., El-Sayed, H. S., \& Fayed, B. (2020). Production of prebiotic chitooligosaccharide and its nano/microencapsulation for the production of $\begin{array}{llll}\text { functional } & \text { yoghurt. Carbohydr. } & 115941 .\end{array}$ https://doi.org/10.1016/j.carbpol.2020.115941.

Lecerf, J. M., Dépeint, F., Clerc, E., Dugenet, Y., Niamba, C. N., \& Rhazi, L., et al. (2012). Xylo-oligosaccharide (XOS) in combination with inulin modulates both the intestinal environment and immune status in healthy subjects, while XOS alone only shows prebiotic properties. Br. J. Nutr. 108, 1847-58 https://doi.org/10.1017/s0007114511007252.

Maftei, N. M. (2019). Probiotic, Prebiotic and Synbiotic Products in Human Health, in: Frontiers and New Trends in the Science of Fermented Food and Beverages; IntechOpen, London, UK. pp. 1-20. https://doi:10.5772/intechopen.81553.

https://www.intechopen.com/books/frontiers-and-new-trends-in-the-science-of- fermented-food-and-beverages/probiotic-prebiotic-and-synbiotic-products-inhuman-health.

Muzzarelli, R. A. (1993). Biochemical significance of exogenous chitins and chitosans in animals and patients. Carbohydr. polym. 20, 7-16 https://doi.org/10.1016/0144-8617(93)90027-2.

Ouwehand, A. C., \& Vaughan, E. E. (2006). The normal microbiota of the human gastrointestinal tract: history of analysis, succession, and dietary influences, in: Gastrointestinal microbiology. CRC press. 2006 pp. 68-90. http://centaur.reading.ac.uk/13156.

Report and data, Market Research Company. (2019) https://www.globenewswire.com/newsrelease/2019/10/16/1930796/0/en/Prebioti c-Ingredients-Market-To-Reach-USD-8-34-Billion-By-2026-Reports-And

Data.html/ Accessed 13 February 2019.

Report FAO/WHO (2001). Probiotics in food: Health and nutritional properties and guidelines for evaluation. 2001. p. 1-29. https://www.who.int/foodsafety/fs_management/en/probiotic_guidelines.pdf. Sanders, M. E., Jackson, S., Schoeni, J. L., Vegge, C., Pane, M., Stahl, B., et al. (2019). Improving end-user trust in the quality of commercial probiotic products. Front. microbiol. 10, 739. https://doi.10.3389/fmicb.2019.00739.

Scott, K. P., Gratz, S. W., Sheridan, P. O., Flint, H. J. \& Duncan, S. J. (2013). The influence of diet on the gut microbiota. Pharm. Res. 69, 52-60 https://doi.org/10.1016/j.phrs.2012.10.020.

Shimizu, K., Yamada, T., Ogura, H., Mohri, T., Kiguchi, T., \& Fujimi, S., et al (2018). Synbiotics modulate gut microbiota and reduce enteritis and ventilatorassociated pneumonia in patients with sepsis: a randomized controlled trial. $J$. Crit. Care. 22, 239. https://doi.org/10.1186/s13054-018-2167-x

Staudacher, H. M., \& Whelan, M. (2016). Altered gastrointestinal microbiota in irritable bowel syndrome and its modification by diet: probiotics, prebiotics and the low FODMAP diet. P. Nutr. Soci. 75, 306-18. https://doi.org/10.1017/S0029665116000021.

Vulevic, J., Tzortzis, G., Juric, A., \& Gibson, G. R. (2018). Effect of a prebiotic galactooligosaccharide mixture (B-GOS $\mathbb{R}$ ) on gastrointestinal symptoms in adults selected from a general population who suffer with bloating, abdominal pain, or flatulence. J, Neurogastroenterol Motil. 30:e13440. https://doi.org/10.1111/nmo.13440.

Westfall, S., Lomis, N., \& Prakash, S. (2018). A novel polyphenolic prebiotic and probiotic formulation have synergistic effects on the gut microbiota influencing Drosophila melanogaster physiology. Artif Cell Nanomed B. 46, 44155. https://doi.org/10.1080/21691401.2018.1458731.

Yurrita, L. C., Martín, I. S., Calle-Purón, M. E., \& Cabria, M. H. (2014). Effectiveness of inulin intake on indicators of chronic constipation; a metaanalysis of controlled randomized clinical trials. Nutr. hosp. 30, 244-52. https://doi.10.3305/nh.2014.30.2.7565. 